\title{
beta-Adrenergic stimulation of skeletal muscle metabolism in relation to weight reduction in obese men
}

\author{
Citation for published version (APA):
}

Blaak, E. E., van Baak, M. A., Kemerink, G. J., Pakbiers, M. T., Heidendal, G. A. K., \& Saris, W. H. M. (1994). beta-Adrenergic stimulation of skeletal muscle metabolism in relation to weight reduction in obese men. American Journal of Physiology (Consolidated), 267(2), E316-E322.

https://doi.org/10.1152/AJPENDO.1994.267.2.E316

Document status and date:

Published: 01/01/1994

DOI:

10.1152/AJPENDO.1994.267.2.E316

Document Version:

Publisher's PDF, also known as Version of record

\section{Please check the document version of this publication:}

- A submitted manuscript is the version of the article upon submission and before peer-review. There can be important differences between the submitted version and the official published version of record. People interested in the research are advised to contact the author for the final version of the publication, or visit the DOI to the publisher's website.

- The final author version and the galley proof are versions of the publication after peer review.

- The final published version features the final layout of the paper including the volume, issue and page numbers.

Link to publication

\footnotetext{
General rights rights.

- You may freely distribute the URL identifying the publication in the public portal. please follow below link for the End User Agreement:

www.umlib.nl/taverne-license

Take down policy

If you believe that this document breaches copyright please contact us at:

repository@maastrichtuniversity.nl

providing details and we will investigate your claim.
}

Copyright and moral rights for the publications made accessible in the public portal are retained by the authors and/or other copyright owners and it is a condition of accessing publications that users recognise and abide by the legal requirements associated with these

- Users may download and print one copy of any publication from the public portal for the purpose of private study or research.

- You may not further distribute the material or use it for any profit-making activity or commercial gain

If the publication is distributed under the terms of Article $25 \mathrm{fa}$ of the Dutch Copyright Act, indicated by the "Taverne" license above, 


\title{
$\beta$-Adrenergic stimulation of skeletal muscle metabolism in relation to weight reduction in obese men
}

\author{
E. E. BLAAK, M. A. VAN BAAK, G. J. KEMERINK, \\ M. T. W. PAKBIERS, G. A. K. HEIDENDAL, AND W. H. M. SARIS \\ Department of Human Biology, University of Limburg and Departments of Radiology and of \\ Nuclear Medicine, University Hospital Maastricht, 6200 MD Maastricht, the Netherlands
}

Blaak, E. E., M. A. van Baak, G. J. Kemerink, M. T. W. Pakbiers, G. A. K. Heidendal, and W. H. M. Saris. $\beta$-Adrenergic stimulation of skeletal muscle metabolism in relation to weight reduction in obese men. Am. J. Physiol. 267 (Endocrinol. Metab. 30): E316-E322, 1994.-In a companion study [Blaak, E. E., M. A. van Baak, G. J. Kemerink, M. T. W. Pakbiers, G. A. K. Heidendal, and W. H. M. Saris. Am. J. Physiol. 267 (Endocrinol. Metab. 30): E306-\$315, 1994.], we found that during infusion of the nonselective $\beta$-agonist isoprenaline (Iso), obese males had a lowered Iso-induced rise in arterial glycerol and nonesterified fatty acids (NEFA) and a lowered muscle NEFA oxidation. The present study was intended to investigate whether a period of weight reduction would alter this impaired fat utilization in obese males. Before and after a 5 -wh diet intervention (very low calorie diet) whole body energy expenditure was determined during rest and during intravenous infusion of increasing doses of Iso. In addition, forearm muscle metabolism was investigated with Iso infusion with and without simultaneous infusion of the $\beta_{1}$-blocker atenolol (A'l') by measuring skeletal muscle blood flow and arteriovenous concentration differences of various metabolites across muscle. The Iso-induced whole body thermogenesis tended to increase as a result of weight loss when this response was related to the plasma Iso concentration $(P=0.09)$, whereas both before and after diet there were no changes in the respiratory exchange ratio during Iso infusion. The increases in arterial NEFA and glycerol concentrations as a result of Iso infusion were not significently different before and after weight reduction. In addition, muscle NEFA uptake did not change as a result of Iso or Iso plus AT infusion both before and after diet, whereas muscle glucose uptake and lactate release tended to be more pronounced after weight reduction. 'Ihese data suggest that a diminished capacity to utilize fat may rather be a primary factor leading to the development of overweight than a secondary factor resulting from the obese state.

obesity, weight reduction, beta-adrenergic stimulation, skeletal muscle metabolism, and impaired fat utilization.

EXPERIENCE INDICATES THAT the reduced obese state is a limited accomplishment, since in most subjects weight regain occurs within measurable time. A factor responsible for this quick weight regain may be that some subjects have a (genetic) predisposition for developing overweight. This predisposition has been suggested to lie in a lowered metabolic rate (17) or a reduced fat-tocarbohydrate oxidation ratio $(18,25)$, which makes individuals prone to obesity when consuming a high-fat diet as in the Western world. The sympathetic nervous system is one of the mediators of energy and substrate metabolism, exerting its effect on thermogenesis via $\beta_{1}$ and $\beta_{2}$-adrenoceptors (4). In addition, catecholamines may play an important role in the mobilization and use of the fat stores $(2,5)$. Several recent studies suggest that obesity may be associated with an impaired ability to oxidize fat $(15,23)$, which may result in the maintenance or development of large fat stores. In agreement with this, we showed in a previous study (3) that during $\beta$-adrenergic stimulation the utilization of fat seems to be impaired in obese men. This was reflected by a decreased mobilization of nonesterified fatty acids (NEFA) and glycerol from adipose tissue and a decreased skeletal muscle NEFA uptake. However, it is difficult to assess the pathophysiological abnormalities leading to obesity when the obese state has already developed, since after the obese state has been developed, it is impossible to differentiate between primary and secondary factors. To obtain more insight into the etiology of obesity, the previously studied obese subjects were restudied after a period of weight reduction. In the present study, data on skeletal muscle substrate utilization were compared in obese subjects before and after a period of weight reduction by a very low calorie diet.

\section{SUBJECTS AND METHODS}

This study was performed in six obese male volunteers, aged $31.1 \pm 1.7 \mathrm{yr}$, all of whom were normotensive and in good health as assessed by a medical history and physical examination. Subject characteristics are indicated in Table 1. The study protocol was reviewed and approved by the Ethics Committee of the University of Limburg, and all volunteers gave written consent. The subjects followed a very low calorie diet for $4 \mathrm{wk}$ and returned in the 5 th wk in 2-3 days to a siluation of energy balance. Before and after this 5 -wk intervention period, measurements were done on whole body thermogenesis and skeletal muscle metabolism, with 2 wk in between measurements. For the measurement of the $\beta$-adrenergically mediated thermogenesis the nonselective $\beta$-agonist isoprenaline (Iso) was infused in increasing standardized doses, and during each infusion period plasma concentrations of Iso and whole body energy expenditure were determined (Iso infusion test). Forearm skeletal muscle metabolism was investigated during Iso infusion with and without simultaneous infusion of the $\beta_{1}$-blocker atenolol (AT) in six subjects of the first study. To improve the accuracy of the skeletal muscle experiment, the dose of Iso infused in this experiment was individually determined from the data of the first experiment as the dose that increased plasma Iso to a fixed concentration of 165 $\mathrm{pg} / \mathrm{ml}$, which is known to increase energy expenditure by $\sim 15 \%$ (4). The dose in the text is related to Iso sulfate, $69 \%$ of which corresponds to Iso free base.

\section{Body Composition}

Body density was determined before and after weight loss by means of hydrostatic weighing with simultaneous lung volume measurement (Volugraph 2000; Mijnhardt). Body composition was calculated according to the equation of Siri (20). 
Table 1. Physical characteristics of the subjects before and after weight loss

\begin{tabular}{lcc}
\hline & Before & After \\
\hline Weight, $\mathrm{kg}$ & $112.3 \pm 10.4$ & $104.2 \pm 10.6^{\mathrm{c}}$ \\
Body mass index, $\mathrm{kg} / \mathrm{m}^{2}$ & $33.3 \pm 2.8$ & $30.9 \pm 2.9^{\mathrm{b}}$ \\
Body fat, $\%$ & $32.3 \pm 2.3$ & $28.3 \pm 2.9^{\mathrm{b}}$ \\
Fat mass, $\mathrm{kg}$ & $37.3 \pm 6.4$ & $30.9 \pm 6.8^{\mathrm{c}}$ \\
Fat-free mass, $\mathrm{kg}$ & $75.0 \pm 4.3$ & $73.3 \pm 4.1^{\mathrm{n}}$ \\
\hline
\end{tabular}

Values are means $\pm \mathrm{SE} ; n=6$ obese subjects. Student's paired $t$ test ${ }^{\mathrm{a}} P<0.05,{ }^{\mathrm{b}} P<0.01,{ }^{\mathrm{c}} P<0.001$.

\section{Diet}

During the first $4 \mathrm{wk}$ of the diet period the subjects followed a very low calorie diet of $2,000 \mathrm{~kJ} /$ day, which provided (in $\mathrm{g} /$ day) 52 protein, 50 carbohydrate, 7 fat, and 1.3 sodium, and a micronutrient content which meets the Dutch recommended daily allowances. In the 5 th wk the subjects returned in $2-3$ days to their habitual eating pattern. The measurements on whole body thermogenesis and forearm metabolism were repeated after the subjects had been weight stable for at least $4-5$ days.

\section{Iso Infusion Test}

In this experiment, Iso was infused in increasing doses of 6 , 12,23 , and $46 \mathrm{ng} \cdot \mathrm{kg}$ fat-free $\mathrm{mass}^{-1}(\mathrm{FFM}) \cdot \mathrm{min}^{-1}$, each dose for $30 \mathrm{~min}$. The dose is related to Iso sulfate, $69 \%$ of which corresponds to Iso free base. Body density was determined by hydrostatic weighing with simultaneous lung volume measurement (Volugraph 2000; Mijnhardt). Whole body energy expenditure was measured by an open-circuit ventilated hood system (Oxycon Beta, Mijnhardt). The abbreviated formula of Weir (24) was used for calculating energy expenditure. After $15 \mathrm{~min}$ in each infusion period, a venous blood sample was taken with a heparinized syringe and was put into a glutathione-containing tube in ice. The sample was immediately centrifuged at 3,000 revolutions $/ \mathrm{min}(\mathrm{rpm})$ at $4^{\circ} \mathrm{C}$, and the plasma was stored at $-50^{\circ} \mathrm{C}$. In the plasma samples, concentrations of Iso, epinephrine (Epi), and norepinephrine (NE) were determined by high-performance liquid chromatography (21). During the experiments, heart rate was recorded continuously. When the heart rate had risen 30 beats/min the infusion was stopped.

\section{Forearm Muscle Experiment}

Design. Forearm skeletal muscle metabolism was investigated with infusion of the nonselective $\beta$-agonist Iso with and without simultaneous infusion of the $\beta_{1}$-blocker AT. After 30 min of supine rest, skeletal muscle blood flow (SMBF) and arteriovenous concentration differences of various metabolites across muscle were determined (see Clinical methods and Biochemical methods). After the control period, the Iso infusion was started for $60 \mathrm{~min}$ with AT added the last $30 \mathrm{~min}$. The above-mentioned measurements were repeated after $30 \mathrm{~min}$ of Iso infusion and after $30 \mathrm{~min}$ of simultaneous Iso and $\mathrm{AT}$ infusion. For each subject, a dose of Iso $\left(\mathrm{ng} \cdot \mathrm{kg} \mathrm{FFM}^{-1} \cdot \mathrm{min}^{-1}\right)$ corresponding to a plasma concentration of $165 \mathrm{pg} / \mathrm{ml}$ was infused. The mean infusion rate of Iso was $19.8 \pm 1.7 \mathrm{ng} \cdot \mathrm{kg}$ $\mathrm{FFM}^{-1} \cdot \mathrm{min}^{-1}$ before and $21.2 \pm 3.6$ after diet. Before the simultaneous infusion of Iso and AT $\left(0.11 \mathrm{mg} \cdot \mathrm{kg} \mathrm{FFM}^{-1} \cdot \mathrm{h}^{-1}\right)$ started, a priming dose of AT $(0.08 \mathrm{mg} / \mathrm{kg}$ FFM) was administered within $5 \mathrm{~min}$. The changes in forearm SMBF were determined by measuring total forearm blood flow (TBF), skin and subcutaneous adipose tissue blood flow (ATBF), and forearm composition.
Clinical methods. Before the start of the experiment, three canulas were inserted. For sampling of arterial blood a canula was inserted in the radial artery of the forearm under local anesthesia. In the same arm, a second canula was inserted in a forearm antecubital vein for the infusion of Iso and AT. In the contralateral arm, a catheter was inserted in retrograde direction of the antecubital vein of the forearm for sampling of deep venous blood.

TBF was measured by venous occlusion plethysmography (26) with a mercury strain gauge (Periflow 0699; Janssen Scientific Instruments). The strain gauge was placed around the forearm, which contained the deep venous catheter. Because this method measures percent change in volume, the blood flow is related to $100 \mathrm{ml}$ forearm tissue. Before measurement of TBF, the hand circulation was occluded by inflating a pediatric sphygnomanometer cuff, placed around the wrist, to a pressure of $200 \mathrm{mmHg}$. In this way, TBF could be assessed without interference from the hand circulation. The venous occlusion cuff, placed around the upper arm, was automatically inflated (and deflated) to a pressure of $40 \mathrm{mmHg}$. 'TBF was recorded approximately every $4 \mathrm{~s}$ (depending on heart. rate) for $1.5 \mathrm{~min}$, and the consecutive (stable) values during the last minute were averaged.

Subcutaneous ATBF was measured after a subcutaneous deposition of ${ }^{133} \mathrm{Xe}$ on the dorsal side of the forearm $\sim 10 \mathrm{~cm}$ proximal to the wrist joint (13). A dose of 5.5 MBq $(150 \mu \mathrm{Ci})$ ${ }^{133 \mathrm{Xe}}$ was dissolved in saline $(0.1-0.15 \mathrm{ml})$ and was injected subcutaneously with a very fine needle $(0.5 \times 16 \mathrm{~mm})$. The arm was placed in a fixed position close to a large-field-of-view gamma camera (Technicare large field 438 HR; General Electrics, Utrecht, The Netherlands). 'The registration of the ${ }^{13} 3$ Xe disappearance was started $45 \mathrm{~min}$ after injection to obtain a monoexponential washout. Fat tissue blood flow was calculated from the disappearance constant of ${ }^{133} \mathrm{Xe}$ over the last 20 min of each infusion period. It was assumed that the blood-tissue partition coefficient of Xe was $8 \mathrm{ml} / \mathrm{g}$ in obese subjects before and after weight loss. For the conversion of ATBF values from $100 \mathrm{~g}$ to $100 \mathrm{ml}$ tissue, the density of adipose tissue was assumed to be $0.9 \mathrm{~g} / \mathrm{ml}$ both before and after diet $(7,20)$.

Before the measurement of TBF, skin blood flow was determined by the laser Doppler technique (Periflux PF3; Perimed) with an occluded hand circulation. The probe was placed on the ventral side of the forearm near the wrist joint. Becatuse the laser doppler method only gives flow in relative units, for calculating absolute blood flow the resting skin blood flow was assumed to be $5 \mathrm{ml} \cdot 100 \mathrm{ml}^{-1} \cdot \mathrm{min}^{-1}(19)$.

The amounts of subcutaneous fat, bone, and muscle of the forearm were determined before and after diet by a crosssectional analysis at the site of the greatest circumference of the forearm with magnetic resonance imaging (MRI; Gyroscan T5; Philips Medical Systems). In our MRI images, we could not detect the amount of forearm skin or distinguish between muscle and tendons. Therefore, the relationship between the total amount of forearm skin and the total area of muscle and subcutaneous fat was assumed to be constant and was assumed to be as described by Cooper et al, (7). The amount of tendon was calculated in a similar way by relating its amount to the amount of muscle. Under the heading of fat and muscle are also grouped nerves and blood vessels within the tissues.

Biochemical methods. Blood samples were taken simultaneously from the artery and the deep forearm vein after the blood flow measurement; while the hand circulation was still occluded. 'Triplicate samples of arterial and deep venous blood were immediately deproteinized with ice-cold sulfosalicylic acid $(3.5 \% \mathrm{wt} / \mathrm{vol})$ in a ratio of one to two, respectively. The 
samples were centrifuged at $3,000 \mathrm{rpm}$ at $4^{\circ} \mathrm{C}$. In the supernatant, concentrations of glucose, pyruvate, lactate, $\beta$-hydroxybutyrate $(\beta-\mathrm{OHB})$, glutamate, alanine, and glutamine were determined with enzymatic assays automated on the Cobas Bio centrifugal analyzer at $355 \mathrm{~nm}(8)$. All assays were carried out using $0.2 \mathrm{M}$ tris(hydroxymethyl)aminomethane-hydrazine buffer, pH 9.2, except for pyruvate, which was done with $1 \mathrm{M}$ phosphate buffer, pH 7. Plasma NEFA and glycerol were measured using standard enzymatic techniques automated on the Cobas Bio centrifugal analyzer.

The concentration of hemoglobin $(\mathrm{Hb})$ in blood and the percentage saturation of $\mathrm{Hb}$ with $\mathrm{O}_{2}$ were measured with a hemoximeter (OSM2 hemoximeter; VA Howe Radiometer, Copenhagen, Denmark). The hematocrit was determined using a microcapillary system.

Calculations and Statistics. SMBF was calculated by the following formula

TBF $=$ amount of muscle $\times$ SMBF + amount of skin

$$
\times \mathrm{SBF}+\text { amount of fat } \times \text { A'TBF }
$$

(amount of tissue: \% total forearm area/100

units blood flow: $\mathrm{ml} \cdot 100 \mathrm{ml}$ tissue $\mathrm{e}^{-1} \cdot \mathrm{min}^{-1}$ )

where SBF is skin blood flow.

The exchange of metabolites across muscle (nmol $100 \mathrm{ml}$ muscle tissue $e^{-1} \cdot \min ^{-1}$ ) was calculated by multiplying the arteriovenous difference of metabolites $(\mu \mathrm{mol} / \mathrm{l})$ by muscle blood tlow $\left(\mathrm{ml} \cdot 100 \mathrm{ml}\right.$ muscle tissue $\left.\mathrm{m}^{\mathrm{m}} \cdot \mathrm{min}^{-1}\right)$. The exchange of NEFA and glycerol was calculated by multiplying their plasma arteriovenous difference by plasma flow (muscle blood flow (1 - hematocrit/100)]. A positive flux indicates uptake.

Data are represented as means \pm SE. Both before and after diet the effect of the infusions on various parameters was analyzed with repeated-measurements analysis of variance. Post hoc testing was done with a Student's paired $t$ test, and the $P$ values of the post hoc comparisons were corrected according to Bonferroni's inequalities. For the comparison of the data of the Iso infusion test (increasing doses) before and after diet, the responses to the infusion were calculated as integrated area under the curve. Comparisons between values before and after diet were done with a Student's paired $t$ test. $P<0.05$ was regarded as statistically significant.

\section{RESULTS}

\section{Body Composition}

As indicated in Table 1 , there was a significant decrease in body weight, fat mass, and FFM as a result of the very low calorie diet. The $8.1 \mathrm{~kg}$ body wt loss can be accounted for $79 \%$ by loss of fat mass and $21 \%$ by loss of FFM.

\section{Iso Infusion Test}

Due to our criteria for stopping the infusion when heart rate had risen 30 beats/min, only two subjects completed all doses after weight loss. The data on the highest infusion dose of Iso are therefore excluded from Fig. 1. Figure 1 shows the changes in energy expenditure, respiratory exchange ratio (RER), and plasma Iso concentration as a result of infusion of increasing doses of Iso. Resting energy expenditure decreased as a result of weight loss $(6.63 \pm 0.57$ vs. $5.74 \pm 0.45 \mathrm{~kJ} / \mathrm{min}$, $P<0.001)$, also when expressed per. FFM $(0.093 \pm 0.002$
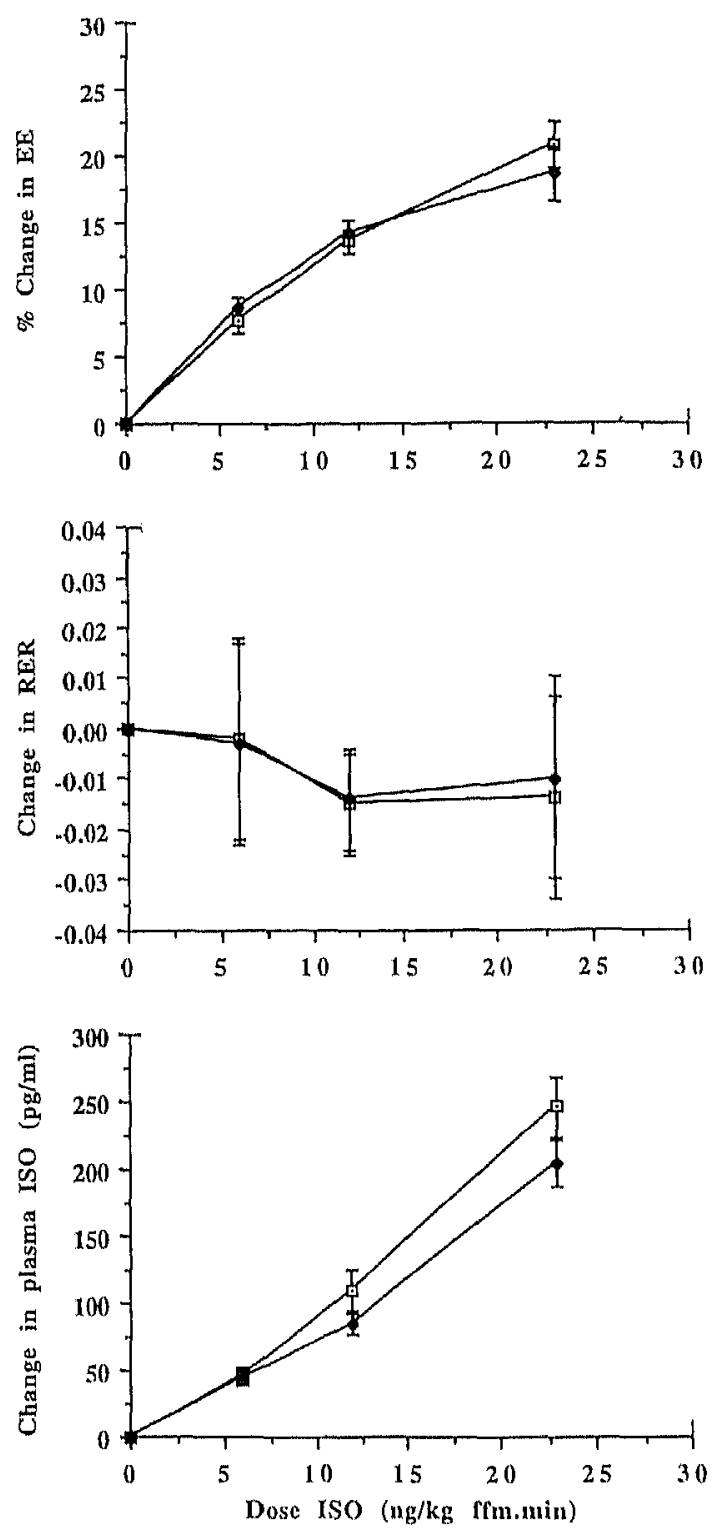

Fig. 1. Changes in onergy expenditure (EE, as \%change), respirntory exchange ratio (RER), and plasma isoprenaline (Iso) concentration with infusion of increasing doses of nonselective $\beta$-agonist Iso before (II) and after $(\$)$ weight loss. Mean $\pm \mathrm{SE}, n=6$ subjects; Repoatedmeasurements analysis of variance: \%change in EN, $P<0.001$. plasma Iso, $P<0.001$. FFM, fat-free mass.

vs. $\left.0.084 \pm 0.003 \mathrm{~kJ} \cdot \mathrm{kg} \mathrm{FFM}-1 \cdot \min ^{-1}, P<0.01\right)$. There were no significant differences in the percentage increase in resting energy expenditure during Iso infusion when this response was related to the administered dose of Iso (per kg FFM, Fig. 1). Resting values for the RER were similar before and after diet $(0.820 \pm 0.016$ vs. $0.824 \pm 0.010)$. Both before and after diet, there were no significant changes in the RER during Iso infusion. The increase in plasma Iso concentration tended to be lower after diet compared with before diet (area under the curve; before vs. after: $9,272 \pm 2,030$ vs. $8,132 \pm 1,795 \mathrm{pg} / \mathrm{ml}$ ), but this decrease did not reach statistical significance. There were no significant differences in the basal NE or Epi values or in the Iso-induced changes in the plasma levels of these catecholamines 
before and after diet (basal NE: $181 \pm 19$ vs. $148 \pm 32$ $\mathrm{pg} / \mathrm{ml}$ and basal Epi: $14 \pm 3$ vs. $17 \pm 4 \mathrm{pg} / \mathrm{ml}$, respectively). Both before and after diet, plasma NE significantly increased (at $23 \mathrm{ng} \cdot \mathrm{kg} \mathrm{FFM}^{-1} \cdot \mathrm{min}^{-1}$, before: $246 \pm 22 \mathrm{pg} / \mathrm{ml}$ and after: $204 \pm 17 \mathrm{pg} / \mathrm{ml}, P<0.001$ ), and plasma Epi showed a decrease (at $23 \mathrm{ng} \cdot \mathrm{kg}$ FFM ${ }^{-1} \cdot \mathrm{min}^{-1}$, before: $10 \pm 3 \mathrm{pg} / \mathrm{ml}$ and after: $10 \pm 4$ $\mathrm{pg} / \mathrm{ml}, P<0.01$ ), as described before (3).

Relating the Iso-induced changes in resting energy expenditure to the plasma Iso concentration yields a slightly increased thermogenic response in five out of the six subjects when expressed as a percentage increase from resting energy expenditure (at plasma Iso 165 $\mathrm{pg} / \mathrm{ml}, n=6$, before: $15.8 \pm 2.8$ vs. after: $18.6 \pm 2.1 \%$, $P=0.09$ ) or as an increase in energy expenditure per kilogram FFM (at plasma Iso $165 \mathrm{pg} / \mathrm{ml}, n=6$, $0.014 \pm 0.003$ vs. $0.017 \pm 0.003 \mathrm{~kJ} \cdot \mathrm{kg} \mathrm{FFM}{ }^{-1} \cdot \mathrm{min}^{-1}$, $P=0.10$ ).

\section{Heart Rate}

Basal heart rate tended to be lower after the diet ( $62 \pm 5$ vs. $55 \pm 3$ beats $/ \mathrm{min}, P=0.10$ ). The absolute Iso-induced increase in heart rate (at plasma Iso of 165 $\mathrm{pg} / \mathrm{ml}$ ) was higher after the diet compared with before the diet, although these differences did not reach statistical significance (before vs. after, Iso: $18.9 \pm 2.0$ vs. $26.6 \pm 4.3 \mathrm{beats} / \mathrm{min}$ and Iso + AT: $6.2 \pm 2.3 \mathrm{vs}$. $10.6 \pm 2.8$ beats $/ \mathrm{min}$ ). In addition, the percent increase in heart rate with Iso and Iso plus AT tended to be higher after diet than before diet (before vs. after, Iso: $30.3 \pm 3.1$ vs. $49.6 \pm 10.2 \%, P=0.13 ;$ Iso $+\mathrm{AT}$ : $10.0 \pm 3.6$ vs. $19.9 \pm 6.3 \%$, respectively).

\section{Intermediary Metabolites}

Changes in arterial concentrations of metabolites are indicated in Table 2. The change in lactate concentration with Iso and Iso plus AT was significantly higher after diet than before diet, as shown in Fig. 2. Before and after diet, glucose concentration decreased with Iso plus AT compared with control. The basal concentration of NEFA was significantly lower after diet, whereas the increase in NEFA with Iso was not significantly differ- ent before and after diet, irrespective of whether it is expressed as an absolute increase or increase per kilogram fat mass. With Iso plus AT the plasma NEFA values returned to baseline both before and after diet. Basal glycerol values and the change in glycerol values during Iso and Iso plus AT were not significantly different before and after weight reduction. The increase in whole blood $\beta$-OHB with Iso was significantly lower after weight reduction compared with before reduction $(P<0.05$, Fig. 2$)$ and tended to be lower during Iso plus AT $(P=0.11)$. Basal glutamate, glutamine, alanine, and insulin values and the changes in these concentrations during Iso and Iso plus AT were not significantly different before compared with after diet.

\section{Forearm composition}

The total forearm area was significantly lower after diet than before diet (before vs. after $8,394 \pm 445$ vs. $\left.8,179 \pm 496 \mathrm{~mm}^{2}, P<0.01\right)$. The relative amount of fat, expressed as percentage of total forearm area, was significantly decreased after diet (before vs. after: $19.8 \pm 1.1$ vs. $17.9 \pm 0.9 \%, P<0.01$ ). The relative amount of muscle tended to be higher after weight reduction compared with before $(61.0 \pm 1.1$ vs. $63.0 \pm 0.8 \%, P=0.09)$. The amounts of skin $(9.1 \pm 0.1 \%$ of total forearm area), bone $(4.6 \pm 0.5 \%)$, or tendon $(5.6 \pm 1.0 \%)$ did not significantly change as a result of weight reduction.

\section{Blood Flow}

Basal TBF and SMBF were not significantly different before compared with after weight reduction, whereas fat tissue blood flow was significantly lower after diet (Table 3). The changes in blood flow through the different forearm tissues with Iso and with Iso plus AT were similar before and after weight loss. Both before and after diet the changes in TBF are mainly determined by changes in SMBF.

Table 2. Changes in arterial concentrations of metabolites as result of infusion of the $\beta$-agonist Iso with and without simultaneous infusion of the $\beta_{1}$-blocker AT before and after weight loss

\begin{tabular}{|c|c|c|c|c|c|c|c|c|}
\hline & \multicolumn{2}{|c|}{ Control } & \multicolumn{2}{|c|}{ Iso } & \multicolumn{2}{|c|}{$\mathrm{Iso}+\mathrm{A}^{\mathrm{T}} \mathrm{T}$} & \multicolumn{2}{|c|}{ ANOVA } \\
\hline & Before & After & Before & After & Before & After & Before & After \\
\hline Pyruvate & $62 \pm 19$ & $78 \pm 10$ & $65 \pm 15$ & $70 \pm 8$ & $69 \pm 15$ & $57 \pm 12$ & & 0.09 \\
\hline Lactate & $770 \pm 14$ & $647 \pm 84$ & $736 \pm 82$ & $755 \pm 17$ & $664 \pm 17$ & $703 \pm 101$ & & \\
\hline Glucose & $4,933 \pm 94$ & $5,045 \pm 190$ & $5,013 \pm 83$ & $4,995 \pm 175$ & $4,660 \pm 100^{n, d l}$ & $4,734 \pm 140^{\mathrm{a}}$ & 0.01 & 0.01 \\
\hline NEFA & $660 \pm 53$ & $382 \pm 69^{\circ}$ & $1,206 \pm 61^{\mathrm{b}}$ & $885 \pm 187^{a}$ & $720 \pm 111$ & $430 \pm 119$ & 0.002 & 0.006 \\
\hline Glycerol & $115 \pm 12$ & $92 \pm 8$ & $143 \pm 18$ & $123 \pm 13$ & $89 \pm 13^{n, d}$ & $79 \pm 21$ & 0,005 & 0.06 \\
\hline$\beta-O H B$ & $75 \pm 27$ & $41 \pm 8$ & $207 \pm 56^{a}$ & $70 \pm 16$ & $152 \pm 34$ & $53 \pm 18$ & 0.005 & \\
\hline Glutamate & $140 \pm 10$ & $135 \pm 11$ & $141 \pm 11$ & $1.22 \pm 12$ & $145 \pm 15$ & $130 \pm 13$ & & \\
\hline Alanine & $340 \pm 28$ & $349 \pm 25$ & $306 \pm 27$ & $332 \pm 25^{a}$ & $293 \pm 28^{\prime \prime}$ & $326 \pm 21^{\prime \prime}$ & 0.009 & 0.04 \\
\hline Glutamine & $582 \pm 31$ & $620 \pm 21$ & $610 \pm 43$ & $590 \pm 26$ & $661 \pm 61$ & $580 \pm 21^{\prime \prime}$ & & 0.02 \\
\hline Plasma insulin & $16.8 \pm 4.7$ & $15.3 \pm 3.9$ & $41.8 \pm 12.9$ & $37.4 \pm 8.1^{b}$ & $25.1 \pm 7.1$ & $26.7 \pm 8.0^{4}$ & 0.013 & 0.006 \\
\hline
\end{tabular}

Values are means $\pm \mathrm{SE}$ in $\mu \mathrm{mol} / \mathrm{l}$, except for plasma insulin for which units are $\mathrm{mU} / 1 ; n=6$ subjects. NEFA, nonesterified fatty acid; $\beta$-OHB, $\beta$-hydroxybutyrate. Student's paired $t$ test (Bonferroni's inequalities). Before or after diet, control vs. isoprenaline (Iso), Iso + atenolol (A'T): " $P$ $<0.05$, ${ }^{b} P<0.01$; Iso vs. Iso + AT: ${ }^{\mathrm{d}} P<0.05$; control before vs. after diet: ${ }^{\mathrm{e}} P<0.01 ; P$ values $(<0.05)$ of analysis of variance (ANOVA) of repeated measurements are indicated in right-hand columns. 

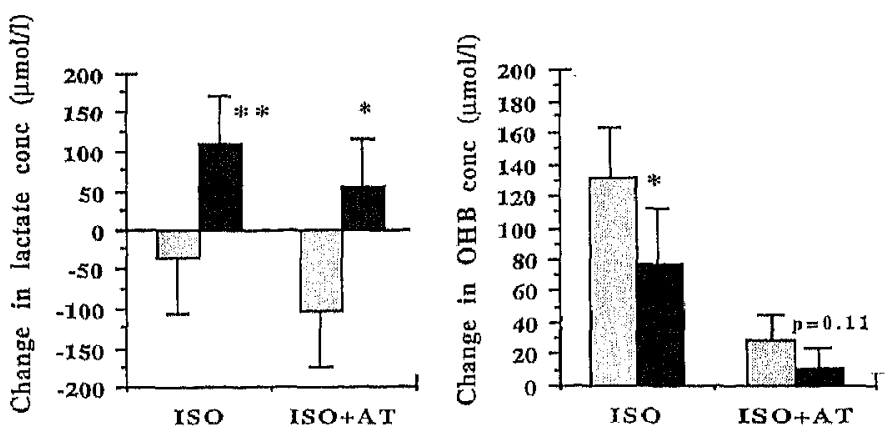

Fig. 2, Changes in arterial lactate and $\beta$-hydroxybutyrate (OHB) concentrations (conc) as result of infusion of nonselective $\beta$-agonist Iso with and without simultaneous infusion of $\beta_{1}$-blocker atenolol (A'T) before and after weight loss. Means \pm SE; $n=6$; Students' paired $t$ test (Bonferroni): * $P<0.05$, ** $P<0.01$.

\section{Skeletal Muscle Substrate Fluxes}

Basal skeletal muscle glucose uptake tended to be lower after diet than before diet $(P=0.13$, Table 4$)$. As a result of weight loss, skeletal muscle glucose uptake tended to be higher with Iso, whereas lactate release tended to be more pronounced. During Iso plus AT, there were no significant changes in glucose or lactate flux as a result of weight reduction. Oxygen, NEFA, glycerol, $\beta-\mathrm{OHB}$, and amino acid fluxes did not significantly change during rest or as a result of Iso or Iso plus $\mathrm{AT}$ infusion both before and after diet.

\section{DISCUSSION}

Recent research indicates that one of the factors contributing to the development of obesity may be an impaired ability to use fat $(18,25)$. In a previous study (3) we found that during Iso obese subjects have a lower fat utilization compared with lean subjects, which was reflected by a lower Iso-induced rise in arterial NEFA and glycerol and in a lower muscle NEFA uptake. The main finding of the present study is that weight loss does not result in an improvement of the Iso-induced lipolysis and muscle NEFA uptake.

\section{Iso-Induced Lipolysis}

The increase in arterial NEFA and glycerol during Iso is similar before and after weight loss, irrespective whether expressed as an absolute increase or as an increase per kilogram fat mass. These Iso-induced increases in NEFA and glycerol were still significantly lower as values previously reported in lean subjects (3).
In addition, the rise in arterial $\beta-\mathrm{OHB}$ was significantly lower after weight loss than before and was also considerably lower than the rise previously reported in lean subjects (3), which indicates a lowered ketogenesis in the reduced obese state. Because the $\beta$-adrenergically mediated ketogenesis is mainly determined by the supply of NEFA to the liver $(2,12)$, these data suggest rather a trend toward a worsening than to an improvement of the lipolytic capacity in the reduced obese state. These findings seem to be in contradiction with data of Leibel et al. (14), who reported an increased lipolytic response to epinephrine infusion in reduced obese subjects. In the latter study the lipolytic response was expressed as a percent increase in basal glycerol concentration, whereas we expressed the lipolytic response both as an absolute increase or as an increase per kilogram fat mass. However, expression of our glycerol data as percent increase from baseline also yields no significant difference in values before and after weight reduction.

\section{Forearm Muscle Metabolism}

Methodological considerations. A factor that may disturb the comparison of forearm skeletal muscle metabolism before and after a diet period is that the composition of the forearm and thus the contribution of the various forearm tissues to TBF may change as a result of weight loss. For this reason, we estimated SMBF by measuring skin blood flow, subcutaneous ATBF, and TBF and by determining forearm composition. Skin blood flow was determined by means of the laser doppler technique, as discussed in the previous paper in lean and obese subjects (3). Both before and after diet, resting skin blood flow was assumed to be 5 $\mathrm{ml} \cdot 100 \mathrm{ml}^{-1} \cdot \mathrm{min}^{-1}$, as reported by Sejrsen (19) at a comparable ambient temperature. Because the relative values for skin blood flow were similar before and after diet, it seems reasonable to assume that there were no large changes in resting skin blood flow as a result of weight loss. Furthermore for calculating subcutaneous ATBF the tissue blood partition coefficient of 1:31 Xe was assumed to be similar before and after diet. We have, however, to take into account that this coefficient may decrease as a result of weight loss due to a decrease in lipid content of adipose tissue. A variation in lipid fraction within the range reported by Bülow et al. (40-90\%; Ref. 5) would give a variation in the partition coefficient from 4.6 to $9.6 \mathrm{ml} / \mathrm{g}$, as can be calculated on

Table 3. Changes in forearm total, skin, sheletal muscle, and subcutaneous fat blood flow as result of infusion of the $\beta$-agonist Iso with and without simultaneous infusion of the $\beta_{1}$-blocker AT before and after weight loss

\begin{tabular}{|c|c|c|c|c|c|c|c|c|}
\hline \multirow{2}{*}{$\begin{array}{l}\text { Blood Flow, } \\
\mathrm{ml} \cdot 100 \mathrm{ml}^{-1} \cdot \mathrm{min}^{-1}\end{array}$} & \multicolumn{2}{|c|}{ Contrul } & \multicolumn{2}{|c|}{ Igo } & \multicolumn{2}{|c|}{ Iso $+A^{\prime} T^{3}$} & \multicolumn{2}{|c|}{ ANOVA } \\
\hline & Before & After & Before & After & Before & Alter & Before & Aftor \\
\hline Tolal & $1.54 \pm 0.41$ & $1.46 \pm 0.42$ & $2.48 \pm 0.37$ & $2.67 \pm 0.75$ & $2.13 \pm 0.33$ & $1.75 \pm 0.36$ & 0.02 & \\
\hline Fat & $1.11 \pm 0.26$ & $0.58 \pm 0.19^{r}$ & $1.56 \pm 0.41$ & $1.33 \pm 0.20^{\mathfrak{n}}$ & $1.04 \pm 0.23$ & $0.92 \pm 0.19$ & & 0.01 \\
\hline Skin & 5.0 & 5.0 & $5.04 \pm 0.59$ & $5.00 \pm 0.1 .3$ & $5.13 \pm 0.58$ & $5.13 \pm 0.24$ & & \\
\hline Skeletal muscle & $1.44 \pm 0.64$ & $1.43 \pm 0.65$ & $2.81 \pm 0.59$ & $3.22 \pm 1.24$ & $2.37 \pm 0.47$ & $1.78 \pm 0.54$ & 0.05 & \\
\hline
\end{tabular}

Values are means $\pm \mathrm{SE} ; n=6$ obese subjects, Paired $t$ test. Comparison of control values, ${ }^{\mathrm{P}} P<0.05$; before or after diet, control vs. Iso, Iso + AT: " $P<0.05 ; P$ values $(<0.05)$ of ANOVA of repeated measurements are indicated in right-hand columns. 
Table 4. Changes in skeletal muscle oxygen consumption and substrate fluxes as result of infusion of the $\beta$-agonist Iso with and without simultaneous infusion of the $\beta_{1}$-blocker AT before and after weight loss

\begin{tabular}{|c|c|c|c|c|c|c|c|c|}
\hline & \multicolumn{2}{|c|}{ Control } & \multicolumn{2}{|c|}{ Iso } & \multicolumn{2}{|c|}{$\mathrm{Iso}+\mathrm{AT}$} & \multicolumn{2}{|c|}{ ANOVA } \\
\hline & Before & After & Before & After & Before & After & Before & After \\
\hline Oxygen & $4.8 \pm 1.1$ & $5.8 \pm 1.9$ & $6.3 \pm 1.3$ & $6.8 \pm 2.0$ & $8.1 \pm 1.3$ & $6.3 \pm 2.2$ & & \\
\hline Pyruvate & $13 \pm 9$ & $44 \pm 15$ & $27 \pm 13$ & $18 \pm 14$ & $40 \pm 8$ & $2 \pm 11$ & 0.11 & 0.04 \\
\hline Lactate & $-109 \pm 117$ & $-74 \pm 93$ & $-308 \pm 239$ & $-278 \pm 90^{\mathrm{a}}$ & $-330 \pm 60$ & $-294 \pm 123^{a}$ & & 0.04 \\
\hline Glucose & $613 \pm 324$ & $424 \pm 275$ & $1,145 \pm 445$ & $1,340 \pm 562$ & $514 \pm 268$ & $467 \pm 181$ & 0.15 & 0.07 \\
\hline NEFA & $-16 \pm 89$ & $57 \pm 23$ & $-18 \pm 171$ & $-39 \pm 89$ & $38 \pm 163$ & $-15 \pm 31$ & & \\
\hline Glycerol & $-8 \pm 15$ & $1 \pm 2$ & $-53 \pm 35$ & $-45 \pm 48$ & $-45 \pm 16$ & $-16 \pm 12$ & & \\
\hline$\beta-\mathrm{OHB}$ & $42 \pm 23$ & $24 \pm 10$ & $158 \pm 60$ & $73 \pm 44$ & $79 \pm 28$ & $25 \pm 10$ & 0.12 & \\
\hline Glutamate & $43 \pm 20$ & $56 \pm 30$ & $105 \pm 28$ & $47 \pm 43$ & $85 \pm 32$ & $64 \pm 26$ & 0.12 & \\
\hline Alanine & $-66 \pm 24$ & $-57 \pm 14$ & $-120 \pm 32$ & $-122 \pm 40$ & $-96 \pm 12$ & $-63 \pm 12$ & & 0.13 \\
\hline Glutamine & $-45 \pm 31$ & $-79 \pm 35$ & $-72 \pm 18$ & $-127 \pm 55$ & $-18 \pm 63$ & $-98 \pm 34$ & & \\
\hline
\end{tabular}

Values are means $\pm \mathrm{SE}$ in nmol $\cdot 100 \mathrm{ml}^{-1} \cdot \min ^{-1}$ except for oxygen consumption for which units are $\mu \mathrm{mol} \cdot 100 \mathrm{ml}{ }^{-1} \cdot \mathrm{min}^{-1} ; n=6 \mathrm{obese}$ subjects. Student's paired $t$ test. Before vs. after, control vs. Iso, Iso+AT: a $P<0.05 ; P$ values of ANOVA of repeated measurements ( $<0.15$ ) are indicated in right-hand columns.

the basis of data of Chen et al. (6). The assumption of a value of 4.6 for the partition coefficient after diet (compared with $8 \mathrm{ml} / \mathrm{g}$ before diet) would yield a more pronounced increase in SMBF (control vs. Iso: $1.50 \pm 0.65$ vs. $3.38 \pm 1.30 \mathrm{ml} \cdot 100 \mathrm{ml}$ muscle tissue ${ }^{-1} \cdot \mathrm{min}^{-1}$ ), would not significantly affect our data on NEFA flux (control vs. Iso: $103 \pm 62$ vs. $-58 \pm 101$ $\mathrm{nmol} \cdot 100 \mathrm{ml}$ muscle tissue ${ }^{-1} \cdot \mathrm{min}^{-1}$ ), and would make the Iso-induced increase in glucose uptake more pronounced ( $503 \pm 266$ vs. $1,562 \pm 662 \mathrm{nmol} \cdot 100 \mathrm{ml}$ muscle tissue $\left.{ }^{-1} \cdot \min ^{-1}\right)$. Thus a correction for the lipid fraction of adipose tissue would only strengthen the main findings of this study. Both before and after weight loss the changes in TBF are mainly determined by changes in muscle blood flow. The use of TBF instead of SMBF would therefore not affect the conclusions of this study.

Muscle substrate utilization. As previously reported, Iso infusion resulted in an increased muscle NEFA uptake and probably oxidation in lean subjects, whereas in the obese subjects glucose was the preferred substrate, and NEFA uptake did not change (3). In the reduced obese state NEFA uptake was still unchanged, which indicates no improvement in the impaired capacity of muscle to take up or oxidize NEFA. In contrast, skeletal muscle glucose uptake tended to be higher after diet compared with before, which indicates a shift toward an improved glucose metabolism in the reduced obese state. The similar basal and stimulated insulin concentrations in combination with a tendency toward an increased skeletal muscle glucose uptake may suggest an increased insulin sensitivity after weight reduction. Indeed, weight reduction by low-calorie diets has been reported to increase insulin sensitivity and to improve glucose metabolism $(9,10)$.

Beside the differences in muscle NEFA oxidation in lean and (reduced) obese subjects, it has previously been reported that skeletal muscle contributes more to the $\beta$-adrenergically induced thermogenesis in lean subjects (3). In lean subjects the Iso-induced increase in muscle oxygen consumption was sufficient to explain the rise in whole body thermogenesis, whereas in the obese the Iso-induced rise in muscle oxygen consumption did not reach statistical significance compared with control values (3). Skeletal muscle oxygen consumption during rest, Iso, and Iso plus AT was similar before and after weight reduction, which indicates that skeletal muscle is still of considerably less importance in the sympathetically mediated thermogenesis in reduced obese than lean subjects. This implicates that, in reduced obese and obese subjects, an important part of the $\beta$-adrenergically mediated thermogenesis must be localized in other tissues, such as adipose tissue, through a possibly increased triglyceride-fatty acid cycling (22).

\section{Iso-Induced Thermogenesis}

Although the mean increases in the thermogenic response and heart rate during Iso (when related to plasma Iso concentration) were not significant after diet in the present study, the individual responses were increased after weight reduction in five out of six subjects, which may suggest a slightly increased $\beta$-adrenergic sensitivity. Resting values of the RER and the RER values during Iso infusion were comparable before and after weight loss, indicating no major changes in the Iso-induced substrate utilization as a result of diet, which is in accordance with the data on skeletal muscle metabolism.

Taken together, the impaired utilization of fat in obesity, as reflected by a decreased Iso-induced lipolysis and muscle fat oxidation, does not improve as a result of weight reduction. These data suggest that the diminished capacity to use fat may rather be a primary factor leading to the development of overweight than a secondary factor as a result of the obese state. Because five out of six of our reduced obese subjects were still overweight, one has to be careful in drawing any definite conclusions from the present study. However, weight reduction resulted in a worsened rather than improved fat utilization, as reflected by the lowered ketogenesis and the tendency toward an increased muscle glucose uptake during Iso, which makes it most unlikely that more severe weight loss would result in a reversal of this trend. The main finding of the present study is in accordance with several other studies in which a diminished fat oxidation has been reported in subjects predis- 
posed to obesity $(18,25)$. One explanation for this diminished capacity to oxidize fat may be a lowered lipolysis, as indicated by the above-mentioned lower Iso-induced increase in NEFA and glycerol values in the reduced obese compared with lean subjects, which may result in a lowered NEFA uptake by muscle (11). The background for the diminished fat utilization in our obese and reduced obese subjects compared with normalweight controls may also lie in a relatively low proportion of slow-twitch type 1 oxidative muscle fibers, utilizing mainly fatty acids, and a relatively high proportion of their fast-twitch glycolytic counterparts $(16,23)$. The mechanisms that may be responsible for the differences in substrate utilization require further research.

Address for reprint requests: E. ミ. Blaak, Dept. of Human Biology, University of Limburg, PO Box 616, 6200 MD Maastricht, The Netherlands.

Received 2 November 1993; accepted in final form 13 April 1994.

\section{REFERENCES}

1. Astrup, A., B. Buemann, N. J. Christensen, and J. Madsen. 24-Hour energy expenditure and sympathetic activity in postobese women consuming a high carbohydrate diet. Am. J. Physiol. 262 (Endocrinol, Metab. 25): E282-E288, 1992.

2. Avogaro, A., P. E. Cryer, and D. M. Bier. Epinephrine's ketogenic effect in humans is medinted principally by lipolysis. Am. J. Physiol. 263 (Endocrinol. Melab. 26): ए250-E260, 1992.

3. Blaak, E. E., M. A. van Baak, G. J. Kemerink, M. T. W. Pakbiers, G. A. K. Heidendal, and W. H. M. Saris. Betaadrenergic stimulation of whole body energy expenditure and forourm skelotal muscle metabolism in loan and obose men. Am. $J$, Physiol. 267 (Enclocrinol. Metab. 30): W306-E315, 1994.

4. Blaak, E. E., M. A. van Baak, K. P. G. Kempen, and W. H. M. Saris. Role of alpha and beta adrenoceptors in the sympatheticallymediated themogenesis. Am. J. Physiol. 264 (Endoerinol. Metal). 27): E11-E17, 1993.

5. Bülow, J., R. Jelnes, A. Astrup, and J. Madsen. Tissue-blood partition coefficients for xenon in various aclipose tissue depots in man. Scand. J. Clin. Lab. Invest. 47: 1-3, 1987.

6. Chen, R. Y., F. Fan, S. Kim, K. Jan, S. Usami, and S. Chien. Tisstre-blood partition coeficient for xenon: temperature and hematocrit dependence. J. Appl. Physiol, 49: 178-183, 1.975.

7. Cooper, K. E., O. G. Edholm, and R. F. Mottram. The blood How in akin and muscle of the human forearm. $J$. Physiol. Lond, 128: $258-267,1965$.

8. Elia, M., P. Folmer, A. Schlatman, A. Goren, and S. Austen. Carbohydrate, fat and protein metabolism in muscle and in the whole body after mixed meal ingestion. Melab Clin. Exp. 37; $542-551,1988$.

9. Gliahou, H. E., J. Laufer, A. Blau, and L. Shulman. Effect of low-calorie diets on the sympathetic nervous system, body weight, and plasma insulin in ovel'weight hypertension. Am. J. Clin. Nutr. 56: $175 \mathrm{~S}-8 \mathrm{~S}, 1992$.
10. Fransilla-Kallunki, A., A. Rissanen, A. Ekstrand, A. Ollus, and L. Groop. Weight loss by very-low-calorie diets: effects on substrate oxidation, energy expenditure and insulin sensitivity in obese subjects. Anu, J. Clin. Nutr, 56: 247S-8S, 1992.

11. Hagenfeldt, L., and J. Wahren. Human forearm muscle metabolism during exercise. II. Uptake, release and oxidation of individual FFA and glycerol. Scand. J. Lab. Invest. 21: 263-276, 1968.

12. Keller, U., M. Lustenberger, J. Müller-Brand, P. P. G. Gerber, and W. Staufffacher. Human ketone body production and utilization studies using tracer techniques: regulation by free fatty acids, insulin, catecholamines, and thyroid hormones. Diabetes Metab. Rev. 5: 285-298, 1989.

13. Larsen, O. A., N. A. Lassen, and F. Quaade. Blood flow through human adipose tissue determined with radioactive xenon. Acta Physiol. Scand. 66: 337-345, 1966.

14. Leibel, R. L., E. M. Berry, and J. Hirsch. Metabolic and hemodynamic responses to endogenous and exogenous catecholaunines in formerly obese subjects. Am. J. Physiol. 260 (Regulatory Integrative Comp. Physiol. 29): R785-R791, 1991.

15. Lillioja, S., J. Foley, C. Bogardus, D. Mott, and B. V. Howard. Free fatty acid metabolism and obesity in man: in vivo and in vitro comparisons. Metab. Clin. Exp. 35: 505-514, 1986.

16. Lillioja, S., A. A. Young, C. L. Culter, J. L. Ivy, W. G. H. Abbot, J. K. Zawadzki, H. Yki-Järvinen, L. Christin, T. W. Secomb, and C. Bogardus. Skeletal muscle capillary density and fiber type are possible determinants of in vivo insulin resistance in man. J. Clin. Invest. 80: 415-424, 1987.

17. Ravussin, E., S. Lillioja, W. C. Knowler, L. Cristin, D. Freymond, W. G. H. Abbott, V. Boyce, B. V. Howard, and C. Bogardus. Reduced rate of energy expenditure as a risk factor for' body weight gain. N. Engl. J. Med. 318:467-472, 1988.

18. Seidell, J. C., D. C. Muller, J. D. Sorkin, and R. Andres. Fasting respiratory exchange ratio and resting metabolic rate as predictors of weighti gain: the Baltimore Longitudinal study on aging. Int. J. Obesity 16: 667-674, 1992.

19. Sejrsen, P. Blood flow in cutaneous tissue studied by washout of radioactive xenon. Circ. Res. 25: 215-229, 1969.

20. Siri W. E. The gross composition of the body. Adv. Biol. Med. Phys, 4: 239-280, 1956.

21. Smedes, F., J. C. Kraak, and H. Poppe. Simple and fust solvent extraction system for selective and quantitative isolation of adrenaline, noradrenaline, and clopamine from plasma and urine. J. Chromalogr. 231: 25-39, 1982.

22. 'Tagliaferro, A. R., S. Dobbin, R. Curi, B. Leighton, L. D. Meeker, and E. A. Newsholme. Effects of diet and exercise on the in vivo rates of triglyceride-fatty acid cycle in adipose tissue and muscle of the rat. Int.J. Obesily 14:957-971, 1990.

23. Wade, A. J., M. M. Marbut, and J. M. Round. Muscle fibre type and aetiology of obesity, Lancel 335: 805-808, 1990.

24. Weir, J. B. New methods for calculating metabolic rate with apecial reference to protein metabolism. J. Physiol. Lond. 109: $1-9,1949$.

25. Zunlo, F., S. Lilioja, A. Esposito-Del Puente, B. L. Nyomba I. Raz, M. F. Saad, B. A. Swinburn, W. C. Knowler, C. Bogardus, and E. Ravussin. Low ratio of fat to carbohydrate oxidation as predictor of weight gain: study of $24-h$ IRQ. Am. IJ. Physiol. 259 (Endocrinol. Melab. 22): E650-E657, 1990. 